\title{
Rancang Bangun Prototype Media Pembelajaran Fisika Berbasis Micro Controller NodeMCU
}

\author{
Fayakun Muchlis, Moh. Toifur \\ Program Pascasarjana (PPs) Pendidikan Fisika Universitas Ahmad Dahlan \\ Kampus 2, Jalan Pramuka 42, Sidikan, Umbulharjo, Yogyakarta. \\ Surat-e : faymuslim@gmail.com
}

Penelitian ini bertujuan menghasilkan prototype media pembelajaran fisika berbasis micro controller NodeMCU. Prototype media pembelajaran fisika tentang Hukum II Newton telah dikembangkan dengan mengkombinasikan sensor IR obstacle, NodeMCU, dan sketch program Arduino IDE sebagai counter waktu dan papan track, kubus berlubang, katrol, benang, dan kepingan logam sebagai perangkat pendukung. Hasil eksperimen telah memperlihatkan nilai percepatan benda pada bidang licin lebih besar daripada bidang kasar. Hasil analisis grafik hubungan percepatan vs resultan gaya eksternal menunjukkkan berbanding lurus dan grafik hubungan percepatan vs massa benda menunjukkan berbanding terbalik. Dengan demikian dapat disimpulkan media pembelajaran fisika berbasis NodeMCU mampu memvisualisasikan, menjelaskan dan membuktikan Hukum II Newton.

\begin{abstract}
This research is aimed to develop a prototype of physics instructional media based on micro controller. Physics learning media about Newton's second law prototype has been developed by combining IR sensor obstacle, NodeMCU, and sketch program the Arduino IDE as counter time, and tracking, block, pulley, rope and metal strip as support device. The experimental results show that the value of acceleration of the object on a slippery plane is larger than the rough plane. The results of the analysis of the acceleration and the resultant graph shows that the external force is directly proportional and a graph showing the acceleration vs the object's mass is inversely proportional. Thus we can conclude that Physics learning media based on NodeMCU is valid in explaining and proving Newton's II.
\end{abstract}

Kata kunci: prototype, alat peraga, hukum II Newton, NodeMCU

\section{Pendahuluan}

Perkembangan Informasi dan Teknologi pada era global dewasa ini telah memberikan dampak di setiap lini kehidupan, tak terkecuali bidang pendidikan. Pendidikan dituntut mengikuti perkembangan era global dengan tetap mempertahankan misi utama yaitu mencerdaskan kehidupan bangsa [I0]. Mewujudkan hal tersebut dapat dimulai pada proses pembelajaran.

Pendidik perlu secara rutin melakukan inovasi pembelajaran dalam proses kegiatan belajar mengajar. Inovasi pembelajaran dapat dilakukan baik dari metode, model, maupun media pembelajaran yang digunakan. Mobile Learning merupakan media pembelajaran yang memanfaatkan perkembangan teknologi dan informasi. Pendidik memanfaatkan hal tersebut dengan memberikan lembaran tugas yang memungkinkan siswa untuk mengakses internet. Hal tersebut senada dengan hasil penelitian yang menunjukan pembelajaran menggunakan mobile learning memberikan dampak positif dalam proses kegiatan belajar mengajar [5]. Inovasi pembelajaran perlu dilakukan sejalan dengan perkembangan IT.

Dewasa ini, perkembangan teknologi informatika memasuki era internet of things (IoT). Jaringan internet yang menghubungkan berbagai objek untuk saling bertukar informasi secara cepat, mudah, dan efisien [4]. Internet telah menjadi konsumsi primer publik, tak terkecuali siswa. Hasil observasi menunjukkan $98 \%$ siswa membawa handphone jenis smartphone ke sekolah. Penggunaan smartphone di kalangan siswa tidak hanya terbatas pada bermain game, berbalas pesan instan, dan streaming namun juga digunakan untuk mencari materi pelajaran. Secara tidak langsung, siswa telah memanfaatkan fasilitas IoT dalam proses pembelajaran. Kebermanfaatan ini tidak seiring dengan minat belajar 
siswa. Ada 7I,8\% siswa memiliki minat belajar terhadap fisika tergolong rendah. Hal ini didukung oleh mindset siswa yang menyatakan pelajaran fisika susah, terutama materi yang berkenaan dengan gerak benda, percepatan, dan vektor. Materi tersebut merupakan pengetahuan dasar untuk mempelajari hukum Newton. Kebermanfaatan IoT dalam proses pembelajaran perlu mendapatkan perhatian lebih dari guru.

Perkembangan IT telah memasuki era Internet of Things (IoT), IoT merupakan suatu jaringan yang menghubungkan berbagai objek yang memiliki identitas pengenal seperti alamat IP sehingga mampu saling berkomunikasi dan bertukar informasi mengenai dirinya maupun lingkungan yang diinderanya [6]. Kehadiran IoT memberikan pengaruh positif dalam dunia pendidikan. Keterbatasan-keterbasan seperti kurangnya alat praktikum atau peraga mampu teratasi dengan fasilitas IoT. Penggunaan IoT mengharuskan berbagai objek yang saling bertukar informasi berada pada area wireless fidelity (wifi). Internet of Things memberikan warna baru dalam pengembangan inovasi pembelajaran..

Inovasi pembelajaran dapat berupa alat peraga, keberadaan alat peraga mampu memudahkan pendidik dalam menyampaikan materi [I]. Hasil observasi pada beberapa sekolah menunjukkan belum tersedianya alat peraga hukum Newton tentang gerak. Siswa mengakui bahwa materi hukum Newton merupakan materi yang sulit dipahami dan membutuhkan media untuk memperjelas materi tersebut. Sedangkan hasil penelitian tentang pengembangan alat peraga hukum newton memperlihatkan hasil positif dengan kualitas produk dan respon sangat baik [6]. Untuk itu, alat peraga hukum Newton akan dikembangkan memanfaatkan fasilitas Internet of Things (IoT).

\section{Kajian Pustaka}

\section{Alat Peraga}

Menurut Dian Indihadi [3] alat peraga adalah alat, simbol, atau lambang yang digunakan untuk meragakan, menirukan, atau menjadikan sesuatu lebih jelas sesuai dengan harapan. Alat peraga sebagai salah satu media pembelajaran merupakan bentuk inovasi yang memungkinkan dilakukan oleh para pendidik. Alat peraga adalah suatu alat yang dapat dilihat oleh mata dan didengar oleh telinga dengan tujuan memyukseskan guru dalam proses belajar mengajar efektif dan menyenangkan [7]. Ada pula yang mengartikan alat peraga sebagai alat yang digunakan untuk memperjelas pelajaran menjadi lebih nyata (konkrit) serta mampu mendorong siswa aktif belajar dalam suasana yang bervariasi dan kreatif [8]. Alat peraga memiliki peran penting dalam transfer pengetahuan selama proses belajar mengajar.
Selain berperan dalam mewujudkan pembelajaran yang efektif, alat peraga juga berperan merangsang imajinasi siswa dan memberikan kesan yang mendalam selama proses belajar. Proses belajar mengajar diawali dengan mempersiapkan tujuan pembelajaran, bahan materi, metode pengajaran, media pembelajaran, dan evaluasi. Penggunaan media pembelajaran seperti alat peraga dalam metode pengajaran merupakan dua hal yang saling terkait. Keterkaitan ini berfungsi untuk memperlancar transfer pengetahuan (materi) agar sesuai dengan tujuan yang dicapai dalam pembelajaran Manfaat alat peraga sebagai media pembelajaran yaitu dapat meniadakan hambatan dimensi ruang dan waktu. Siswa memiliki keleluasaan akses terhadap sumber belajar (alat peraga) yang memungkinkan siswa mampu memahami suatu konsep secara tepat dan menyeluruh terutama tentang hukum kedua Newton

\section{Hukum II Newton}

Keadaan alami suatu benda adalah bergerak dengan kecepatan tertentu karena pengaruh dari luar yang dapat menyebabkan perubahan percepatan pada benda. Kuantitas instrinsik benda yang dikenal dengan istilah massa inersi (m) mampu menyebabkan perubahan kondisi gerak benda. Semakin besar massa benda maka semakin sulit menghasilkan perubahan posisi benda tersebut. Sedangkan pengaruh luar yang menyebabkan berubahnya keadaan gerak suatu benda disebut sebagai gaya $F$. Pengaruh luar (gaya) yang bekerja pada sebuah benda sebanding dengan laju perubahan kuantitas gerak (momentum) terhadap waktu [9]. Sesuai dengan persamaan berikut

$$
\vec{F}=\frac{d \vec{p}}{d t}
$$

dengan $\vec{p}=m \vec{v}$ dan kuantitas massa tidak berubah terhadap waktu, maka persamaan di atas dapat dinyatakan sebagai berikut

$$
\vec{F}=m \vec{a}
$$

Persamaan tersebut merupakan manifestasi dari hukum II Newton tentang gerak benda karena pengaruh dari gaya luar.

$\vec{F}$ = gaya yang bekerja pada benda $(\mathrm{N})$

$\vec{p}=$ momentum benda $\left(\mathrm{kgm} / \mathrm{s}^{2}\right)$

$m$ = massa benda $(\mathrm{kg})$

$\vec{a}=$ percepatan benda $\left(\mathrm{m} / \mathrm{s}^{2}\right)$

Media penyampaian hukum II Newton berupa alat peraga yang berbasis Internet of Things. salah satu hardware yang bekerja menggunakan IoT adalah NodeMCU. 


\section{NodeMCU}

NodeMCU merupakan sebuah open source platform (fondasi program) IoT dan pengembangan kit (alat) yang menggunakan bahasa pemrograman Lua. NodeMCU berfungsi untuk membantu para makers dalam membuat prototype produk IoT dengan menggunakan sketch pada arduino IDE. NodeMCU dikembangkan berdasarkan pada modul ESP8266 yang mengintegrasikan GPIO, PWM, IIC, Wire, dan ADC dalam satu board. Keunikan board ini dilengkapi fitur wifi dan firmware yang bersifat open source. Open source hardware artinya skema dan desain perangkat kerasnya dapat disebarluaskan secara bebas tanpa adanya batasan guna keperluan didesain ulang dan dikembangkan lebih lanjut atau diduplikasi.

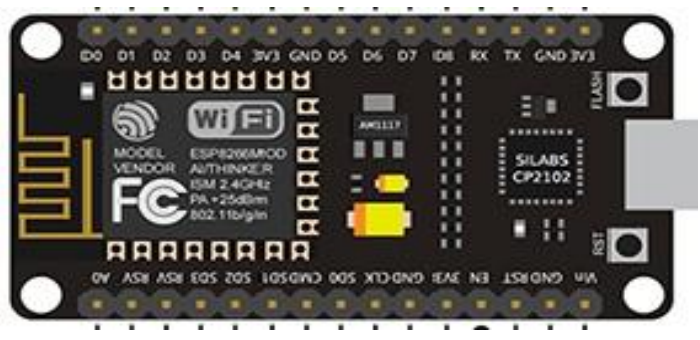

Gambar I NodeMCU tampak depan (Sumber : Acrobotic)

NodeMCU merupakan sebuah board mikrokontroler yang dapat diprogram melalui Arduino IDE. NodeMCU memiliki spesifikasi: I) berbasis pada ESP8266 serial Wifi SoC (single on chip) dengan onboard USB to TTL; 2) 2 tantalum capasitor $I 00$ micro farad dan $I 0$ micro farad; 3) 3,3v LDO regulator; 4) blue led; 5) cp2 I02 usb to UART bridge; 6) tombol reset, port usb, tombol flash; 6) memiliki 9 GPIO (general pin input output) yang didalamnya terdapat 3 pin PWM, I x ADC Channel, dan pin RX TX; 7) 3 pin ground; 8) GPIO dengan arus keluaran masing-masing $15 \mathrm{~mA}$ dengan tegangan 3 volt; 9) Built in 32- bit MCU; I0) board dapat diprogram langsung melalui USB tanpa perlu rangkaian tambahan [I2]. NodeMCU memuat semua yang dibutuhkan untuk berfungsi sebagai mikro kontroler, selain itu NodeMCU mudah dihubungkan ke sebuah komputer dengan kabel USB. Pemograman NodeMCU dapat menggunakan Arduino IDE (Integrated Development Environment).

\section{Metode Eksperimen}

Gunakan Satuan Internasional (MKS) atau CGS Prosedur eksperimen yang dilakukan adalah sebagai berikut :
a) Alat dan bahan dirangkai seperti skema pada gambar 2.
b) Hubungkan kabel usb dengan sumber tegangan.
c) Letakkan balok berlubang tepat didepan sensor I.

d) Lepaskan balok tersebut agar bergerak melintasi ketiga sensor.

e) Catatlah waktu yang terbaca pada agnosthing.com dengan urutan ke-2 sebagai tor dan urutan ke-I sebagai to2.

f) Data waktu yang dibutuhkan yaitu $t_{1}$ dan $t_{2}$, $t_{I}$ adalah waktu tempuh benda pada jarak $S_{I}$ samadengan tor. Sedangkan $t_{2}$ adalah waktu tempuh benda pada jarak $\mathrm{S}_{2}$ yaitu toI $+\mathrm{t}_{22}$.

g) Lakukan langkah tersebut untuk variasi massa benda dan massa beban gantung.

Data yang telah diperoleh berupa waktu tempuh benda melintasi sensor I ke 2 dan sensor 2 ke 3 dianlisa guna memperoleh nilai percepatan benda. Analisis menggunakan persamaan gerak lurus berubah beraturan (GLBB) dengan posisi awal benda diam. persamaan gerak lurus berubah beratur

$$
S=v t+\frac{1}{2} a t^{2}
$$

dengan benda mula-mula diam $v_{o}=0$ maka persamaan tersebut menjadi

$$
S=\frac{1}{2} a t^{2} \text { atau } t^{2}=\frac{2}{a} S
$$

Variabel terikat adalah $t^{2}$. Variabel bebas adalah $S$. Persamaan garis linier $y=m x$ mewakili variabel terikat dan variabel bebas dibuat pada grafik. Nilai gradien $m$ ditentukan dengan

$$
m=\frac{y_{2}-y_{1}}{x_{2}-x_{1}}
$$

Nilai percepatan benda dapat diketahui dengan persamaan berikut

$$
m=\frac{2}{a} \text { atau } a=\frac{2}{m}
$$

Perhitungan dengan menggunakan program ms.Excel.

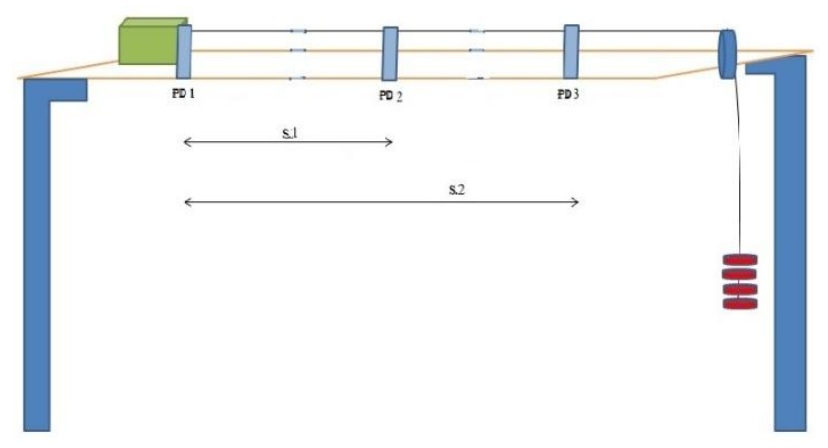

Gambar 2. Skema Rangkaian Alat 


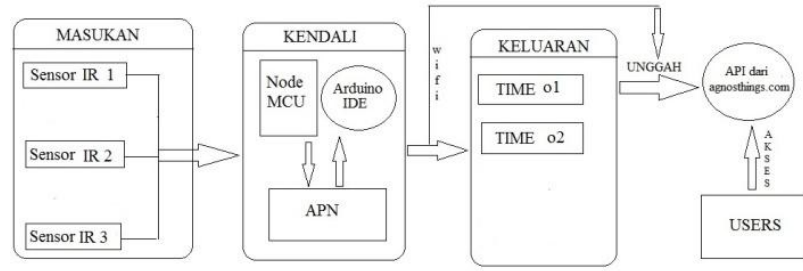

Gambar 3. Skema Rancangan APN NodeMCU

\section{Hasil Penelitian dan Pembahasan}

Telah dikembang sebuah prototype media pembelajaran Fisika berupa alat peraga tentang hukum II Newton sistem katrol. Pembuatan komponen-komponen alat peraga terdiri dari papan bidang datar dengan dua sisi beralaskan mika sebagai bidang licin dan kain flanel sebagai bidang kasar, penggaris berskala, benda bergerak, katrol, dan pengait beban gnatung. Perangkat tersebut dikombinasikan dengan counter time hasil integrasi antara micro controller NodeMCU, sensor IR Obstacle, dan program arduino IDE guna membentuk alat peraga Fisika berbasis IoT.

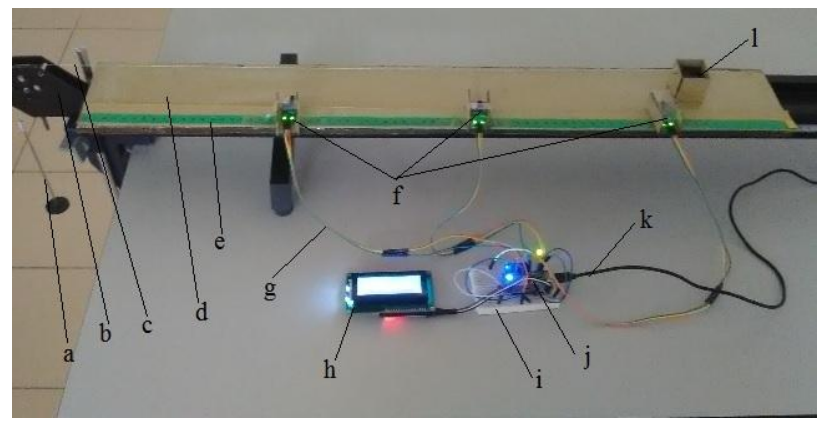

Gambar 4. Alat peraga Hukum II Newton

Keterangan :
a. Pengait beban gantung
h. Kabel jumper
b. Katrol
c. Benang / tali
i. LCD I6x4
d. Papan track
j. Breadboard
e. Penggaris
k. NodeMCU
1. Kabel usb
f. Sensor IR obstacle
m. Balok berlubang

Sebelum melakukan eskperimen, produk divalidasi oleh ahli dengan hasil produk berupa alat peraga Fisika berbasis NodeMCU telah memenuhi komponen media pembelajaran dan mampu menampilkan data praktikum secara real time pada web agnosthings.com serta layak untuk digunakan dengan berbagai saran dari ahli. Saran tersebut antara lain: sensor IR perlu dikemas dengan rapi agar tidak terlalu terbuka, ukuran tombol reset perlu diperbesar, percobaan disesuaikan dengan waktu pembelajaran dengan difasilitasi LKS. Setelah divalidasi oleh ahli dan dinyatakan layak maka produk diujicoba di laboratorium.

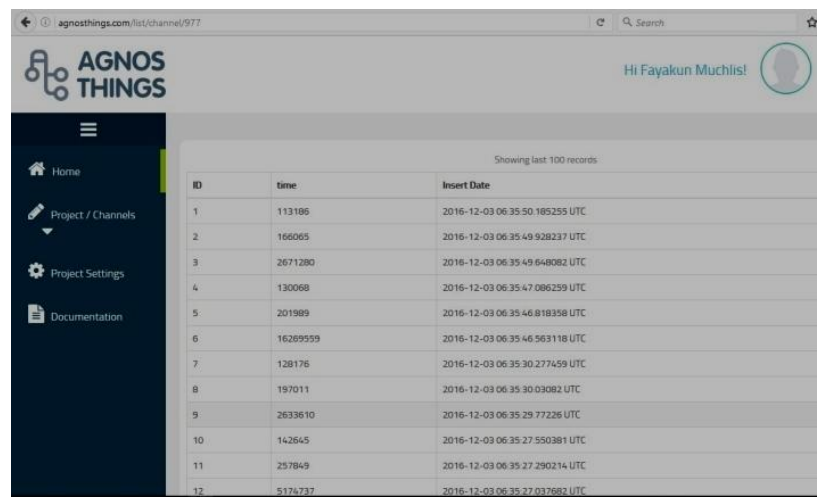

Gambar 5. Tampilan Data pada agnosthings.com

Gambar 5 menampilkan data waktu yang terbaca oleh counter ketika ada benda yang melewati sensor. Data waktu tempuh benda tercatat sebagai tor dan to2 dapat diperoleh users dengan mengakses web agnosthings.com baik melalui smartphone maupun personal computer (PC) masing-masing.

Prototype alat peraga Fisika Hukum II Newton dengan sistem katrol perlu dieksperimenkan guna memperoleh data yang memperlihatkan validitas produk dalam membuktikan hukum II Newton dan keberfungsian masing-masing komponen. Eksperimen dilakukan dengan memvariasikan massa benda yang bergerak dan massa beban yang menggantung. Massa beban gantung berpengaruh pada gaya eksternal yang bekerja pada benda.

Hasil analisis data eksperimen menunjukkan perbedaan nilai percepatan benda di bidang licin dan kasar baik pada saat variasi massa beban gantung maupun massa benda. Percepatan benda pada bidang licin lebih besar daripada bidang kasar. Hal ini terlihat saat gerakan benda pada bidang licin lebih cepat daripada bidang kasar. Hal ini disebabkan pada bidang licin gaya eksternal yang bekerja pada benda hanyalah gaya berat sedangkan pada bidang kasar gaya eksternal yang bekerja pada benda selain gaya berat juga terdapat gaya gesek yang menghambat laju gerak benda sehingga pergerakan benda menjadi lebih lambat. Hasil perbedaan nilai percepatan benda dapat dilihat pada tabel I dan II berikut.

Tabel I. Perbedaan Percepatan Benda Massa Beban gantung Tetap

\begin{tabular}{ccc}
\hline \multirow{2}{*}{$\begin{array}{c}\text { Massa } \\
\text { Benda }(\mathrm{Kg})\end{array}$} & \multicolumn{2}{c}{ Percepatan $\left(\mathrm{m} / \mathrm{s}^{2}\right)$} \\
\cline { 2 - 3 } Bidang Licin & Bidang Kasar \\
\hline 0.016 & 9.381 & 8.153 \\
0.046 & 4.294 & 2.895 \\
0.062 & 2.570 & 1.648 \\
\hline \hline
\end{tabular}


Tabel 2. Perbedaan Percepatan Benda Massa Benda Tetap

\begin{tabular}{ccc}
\hline \multirow{2}{*}{$\begin{array}{c}\text { Massa Beban } \\
\text { Gantung }(\mathrm{Kg})\end{array}$} & \multicolumn{2}{c}{ Percepatan $\left(\mathrm{m} / \mathrm{s}^{2}\right)$} \\
\cline { 2 - 3 } & Bidang Licin & Bidang Kasar \\
\hline $0.0 \mathrm{I}$ & $2 . \mathrm{II} 2$ & 2.100 \\
0.02 & $6.3 \mathrm{I} 2$ & 5.850 \\
0.03 & 9.495 & 8.247 \\
\hline \hline
\end{tabular}

Selain analisis pada percepatan benda pada bidang licin dan kasar, diperoleh juga grafik hubungan antara percepatan dengan massa benda dan percepatan dengan resultan gaya eksternal. Berikut adalah grafik hubungan yang diambil sampel pada gerak benda pada bidang licin.

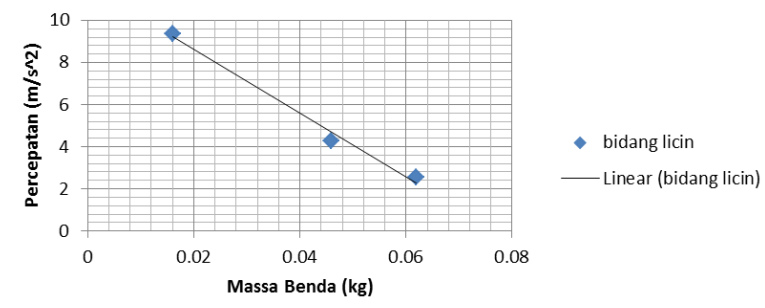

Gambar 6. Diagram grafik percepatan vs massa benda



Gambar 7. Diagram grafik percepatan vs resultan gaya

Pada gambar 6 dan 7 memperlihatkan hubungan antara percepatan dengan massa benda dan resultan gaya eksternal pada bidang licin. Gambar 6 menunjukkan nilai percepatan benda semakin kecil dengan bertambahnya massa benda. Artinya percepatan berbanding terbalik dengan massa benda. Hal ini sesuai dengan pernyataan semakin besar massa benda maka semakin sulit menghasilkan perubahan posisi benda tersebut yang ditunjukkan dengan nilai percepatan yang semakin kecil[9].

Gambar 7 menunjukkan nilai percepatan benda semakin besar dengan bertambahnya resultan gaya yang bekerja pada benda tersebut. Artinya percepatan berbanding lurus dengan resultan gaya eksternal. Hal ini sesuai dengan pernyataan pengaruh luar (gaya) yang bekerja pada sebuah benda sebanding dengan laju perubahan kuantitas gerak (momentum) terhadap waktu yang ditunjukkan semakin cepat laju benda dan nilai percepatan yang semakin besar[9].

Hukum II Newton secara umum dapat dinyatakan sebagai berikut "Apabila ada gaya luar yang bekerja pada benda, maka benda mengalami percepatan yang besarnya sebanding dengan gaya eksternal dan berbanding terbalik dengan massa benda”. Secara umum hasil analisis data eksperimen produk ini telah mampu menjelaskan dan membuktikan konsep hukum II Newton. Hasil data yang diperoleh dari eksperimen menggunakan alat peraga Fisika berbasis NodeMCU dibandingkan dengan alat praktikum hukum II Newton buatan PHYWE dan data eksperimen menunjukkan hasil yang sama dengan perbedaan yang kecil.

\section{Kesimpulan}

Telah dikembangkan prototype media pmebelajaran Fisika berupa alat peraga tentang hukum II Newton berbasis IoT yang dinyatakan layak oleh validator ahli. Media pembelajaran Fisika ini telah mampu menggunakan kemajuan era teknolgi informasi yang berkembang pesat pada era Internet of Things (IoT) dengan board micro controller NodeMCU. Prototype berupa alat peraga juga mampu memvisualisasikan perbedaan gerak benda pada bidang licin dan kasar serta membuktikan konsep dari hukum II Newton.

Keterbatasan produk ini terlihat pada penampilan atau packaging alat peraga yang belum rapi serta pemilihan bentuk benda yang bergerak agar mudah terbaca oleh sensor, masih terdapat sambungan pada bidang kasar berupa kain flanel. Selanjutnya media pembelajaran Fisika ini perlu digunakan dalam pembelajaran di kelas guna memperoleh respon minat dan pemahaman siswa terhadap materi hukum II Newton.

\section{Ucapan Terimakasih}

Penulis mengucapkan terimakasih kepada Laboratorium Fisika Dasar UIN Sunan Kalijaga yang telah menyediakan tempat guna pengambilan data. Kepada Sulis Priyanto yang telah bekerja sama dalam proses pembuatan alat peraga berbasis NodeMCU ini sehingga dapat terselesaikan dengan baik.

\section{Kepustakaan}

[I] Rohayati, A. 2008. Handout : Mata kuliah Media Pembelajaran. Bandung: UPI.

[2] Borg R. Walter and Gall Mereith. 1983. Educational Research $4^{\text {th }}$ edition. Newyork: Longman Inc.

[3] Indihadi, D., Media dan Alat Peraga Dalam Pembelajaran Bahasan Kedua. Diakses pada tanggal I6 Oktober 2016.

[4] Meutia, E.D. 2015. "Internet of Things- Kemanan dan Privasi". Seminar Nasional dan Expo Teknik Elektro ISSN : 2088-9984.

[5] Padli, Irwan. 2016. "Strategi Pembelajaran Efektif Berbasis Mobile Learning Pada Sekolah Dasar. Jurnal Iqra' Volume I0 No.I

[6] Rochaeni, Siti. 2015. "Pengembangan Alat Peraga Fisika SMA Materi Hukum Newton dan Aplikasinya”. Seminar Nasional Fisika (E-Journal) Volume IV : UNJ

[7] Sudjana, Nana. 2002. Dasar-Dasar Proses Belajar Mengajar: Bandung: Sinar Baru Algensindo. 
[8] Surisman. 1998. "Upaya Guru Meningkatkan Kreatifitas Siswa Melalui Alat Pearaga Dalam Proses Belajar Mengajar Matematika di SD 2 Segalaminder Bandar Lampung". Jurnal Penelitian Pendidikan Dasar: IKIP Yogyakarta.

[9] Satriawan, Mirza. 2012. Fisika Dasar. Yogyakarta : UGM

[10] Soedijarto. 2013. Profesionalisme Guru (Pendidik) Dalam Era Globalisasi, Implikasi, Peluang, dan Tantangannya. Diakses di www.ispi.or.id

[II] Tim Puslitjaknov. 2008. Metode Penelitian Pengembangan. Jakarta : Pusat Penelitian Kebijakan dan Inovasi Pendidikan Badan Penelitian dan Pengembangan Departemen Pendidikan Nasional.

[12] Anonim. 2016. Pengenalan NodeMCU ESP8266 Versi I2E. Diakses di dirakit.com 